\title{
Cartografia: aproximação metodológica para produção do conhecimento em gestão de pessoas
}

\author{
Cartography: methodological approach for producing knowledge on people management
}

\author{
Lílian Weber $^{1}$ \\ Carmem Ligia lochins Grisci ${ }^{2}$ \\ Simone Mainieri Paulon ${ }^{3}$
}

Resumo

No âmbito das discussões acerca das possibilidades metodológicas para pesquisas sobre gestão de pessoas, este artigo tem como objetivo apresentar a cartografia como alternativa ao uso dos métodos tradicionais, contribuindo assim para inovar a construção do conhecimento em administração. Ainda pouco explorada nessa área, a cartografia consiste no mapeamento de territórios psicossociais, acompanhando as linhas de força que os constituem. Atenta aos processos que compõem a subjetividade e que se passam entre os estados instituídos, busca abarcar a complexidade da vida, resistindo às tendências reducionistas de métodos simplificadores. Neste artigo descreve-se o percurso metodológico de uma pesquisa que busca não apenas apreender as conexões efetuadas em um blog coletivo ligado a uma política pública, mas também analisar as possibilidades de cooperação na produção do trabalho e de si, concebidas em um contexto de trabalho imaterial. A pesquisa apresentada está sendo desenvolvida na internet, que também se configura como um campo ainda em exploração, sobretudo se considerarmos a abordagem qualitativa. Quanto aos resultados apresentados neste artigo, eles não dizem respeito ao objetivo da pesquisa em andamento, mas às experimentações do método cartográfico tematizado. Diferente de divulgar resultados parciais da investigação inacabada, trata-se do exercício do próprio método: a construção das metas no percurso da investigação. A cartografia prima pela processualidade, o que permite tomar como valioso também o compartilhamento dessa experiência em seus diferentes momentos de produção. No final do artigo, a cartografia é indicada como alternativa aos métodos tradicionais de pesquisa, contribuindo dessa forma para a produção do conhecimento sobre o trabalho no cenário contemporâneo.

Palavras-chave: Pesquisa Qualitativa. Cartografia. Pesquisa na internet. Gestão de Pessoas.

\begin{abstract}
In the domain of discussions on the methodological possibilities for people management research, this paper aims to introduce cartography as an alternative to the use of conventional methods, thus contributing to innovate in the construction of knowledge on administration. Still poorly explored in this field, cartography consists of mapping psychosocial territories, tracking the power lines which constitute them. Aware of the processes which make up subjectivity and take place between established statuses, it seeks to comprise the complexity of life, resisting to the

Artigo submetido em 10 de maio de 2012 e aceito para publicação em 13 de novembro de 2012.

1 Doutora em Administração pela PPGA/EA/UFRGS; Psicóloga do Trabalho da Intercessão: Instituições e Clínica. Endereço: Rua Ramiro Barcelos, 1215 - cj. 401 - Independência, CEP 90035-006, Porto Alegre - RS, Brasil. E-mail: lilian@Iweber.com.br

2 Doutora em Psicologia pela PUC/RS; Professora Associada do PPGA/EA/UFRGS. Endereço: Rua Washington Luiz, 855, Centro, CEP 90010-460, Porto Alegre - RS, Brasil. E-mail: cligrisci@ea.ufrgs.br

3

Doutora em Psicologia Clínica pela PUC - SP; Professora adjunta do PPG de Psicologia Social e do PPG de Saúde Coletiva da UFRGS. Endereço: Rua Ramiro Barcelos, 2.600, sala 212, CEP 90035-003, Porto Alegre - RS, Brasil. E-mail: simonepaulon@gmail.com
\end{abstract}


reductionist trends of simplifying methods. In this paper, one describes the methodological path for a research aimed not only at understanding the connections made in a collective blog related to a public policy, but also at analyzing the possibilities for contributing to the production of work and the self, conceived in a context of immaterial work. The research presented is being carried out on the internet, which also constitutes a field that is currently being explored, particularly when one takes into account a qualitative approach. Regarding the results presented in this paper, they aren't related to the aim of the research in progress, but to experiments of the cartographic method described herein. Instead of announcing partial results of the unfinished investigation, it's the very practice of the method: setting of goals in the investigation path. Cartography is characterized by its procedural nature, something which allows one to regard sharing this experience, at its different production stages, as something valuable, too. At the end of the paper, cartography is indicated as an alternative to conventional research methods, thus contributing to the production of knowledge on work in the contemporary scenario.

Keywords: Qualitative research. Cartography. Search on the internet. People management.

\section{Introdução}

A preocupação com a metodologia de pesquisa é recorrente nas mais diversas áreas do saber, por ser este um aspecto crucial para a produção do conhecimento. Durante muito tempo, e ainda hoje, as escolhas metodológicas têm sido influenciadas pelo paradigma moderno de ciência que, segundo Morin (1983), tende a simplificar e reduzir a complexidade para compreender a realidade de forma ordenada. Isto porque promove a ênfase da consciência, da mitificação da racionalidade e da noção de totalidade, bem como da supervalorização das evidências matemáticas. Mesmo tendo impulsionado uma série de descobertas, esse paradigma hegemônico, quando assumido como único caminho possível que conduz à verdade absoluta de uma realidade dada, reduz as inúmeras possibilidades de investigação, sobretudo, no que diz respeito às ciências sociais e humanas.

No contraponto dessa lógica linear, calcada no que se denomina paradigma da simplificação, encontra-se a busca do conhecimento não dualista, no qual natureza/cultura, objetivo/subjetivo e quantitativo/qualitativo são dicotomizações artificiais que perdem significação diante da complexidade da vida. Considerado em sua transitoriedade, o conhecimento deve driblar certezas e reducionismos para instigar um contínuo questionamento que permita ao investigador aproximar-se da realidade complexa. A abordagem não dualista assume a complexidade como desafio, com suas incertezas, problemas e contradições.

Tal polêmica no que tange à produção do conhecimento também acontece no campo da administração. Vieira (2006) critica o tradicional debate entre pesquisa quantitativa e pesquisa qualitativa. Enquanto à primeira, tradicionalmente, outorga-se o papel de representante do paradigma moderno e hegemônico, a segunda, embora tenha conquistado algum espaço, ainda luta por sua legitimidade. Isso se deve ao fato de que a pesquisa qualitativa está associada à ausência de rigor e cientificidade, o que se deve mais ao uso inadequado do método e não a alguma limitação (VIEIRA, 2006).

De qualquer modo, hoje se reconhece que a dicotomia entre pesquisas quantitativa e qualitativa é uma falsa dicotomia. Segundo Vieira (2006, p. 14), há necessidade de romper com os "monopólios metodológicos", tendo em vista o "evidente aumento da complexidade no campo dos estudos organizacionais e do fenômeno administrativo como fato social". Assim, é indicada a utilização de múltiplos métodos de pesquisa e investigação na análise dos fenômenos administrativos e organizacionais, de forma a abrir novos horizontes para sua compreensão. Reforça-se o pressuposto básico da pesquisa científica de que o método deve estar de acordo com a temática, o problema e os objetivos propostos. Além disso, na escolha do método já está implícita a maneira de encarar o fato social a ser investigado.

No campo específico de gestão de pessoas, Zanelli (2002) realizou levantamento e identificou que poucos estudos utilizavam a abordagem qualitativa, a despeito de seu potencial. Ele considera a pesquisa qualitativa 
interessante pela multiplicidade de procedimentos associados a diferentes posturas teóricas e metodológicas, bem como pela possibilidade de diluição de fronteiras entre ciência, militância e ficção.

Tonelli, Caldas, Lacombe et al. (2003) também realizaram um levantamento sobre as pesquisas na área. Eles desenvolveram um balanço da produção acadêmica em recursos humanos no período de 1991 a 2000 e constataram falta de diversidade epistemológica, assim como limitada variabilidade com relação às escolhas metodológicas, em maior parte fundamentadas em bases funcionalistas. Segundo esses autores, "a frágil base metodológica da área revelada na pesquisa é talvez a mais evidente e desconfortável de todas as constatações preocupantes observadas" (TONELLI, CALDAS, LACOMBE et al., 2003, p. 120). Os autores identificaram uma reduzida produção de conhecimento mais significativo e contributivo para a área e sugerem que a superação de tais limitações deva passar pela revisão de desenho e pretensão metodológica. "Em tempos do clamor pela inclusão social, pela inclusão digital etc., parece ser tempo da área pensar também em inclusão. De outros temas. De outras bases epistemológicas e metodológicas. De outras regiões e de outros pensadores. Não em vez de, mas além de, aqueles que hoje para ela contribuem" (idem).

Com base nessas considerações iniciais, este artigo pretende contribuir com a discussão das possibilidades metodológicas, propondo a utilização de um método de pesquisa amplamente empregado entre estudos da subjetividade, mas ainda pouco explorado na área da administração: o método cartográfico.

Além de sistematizar o referencial teórico que dá embasamento à proposta, o artigo traz o relato de uma pesquisa que está em andamento. Ao fazê-lo, entretanto, não se está simplesmente divulgando resultados parciais de uma investigação inacabada, senão experimentando uma das características do próprio método: a construção das metas do estudo no próprio percurso de investigação. A cartografia prima pela processualidade, o que permite tomar como valioso também o compartilhamento dessa experiência de pesquisa em seus diferentes momentos de produção.

A experiência cartográfica a ser apresentada tem como objetivo apreender as conexões efetuadas em um blog ${ }^{4}$ coletivo na internet e analisar as possibilidades de cooperação na produção do trabalho e de si, concebidas em contexto do trabalho imaterial. Estuda-se, portanto, as relações entre o trabalho na contemporaneidade e a produção de subjetividade, que impacta, como se verá adiante, não apenas "horas de trabalho", mas a vida, integralmente. O desenvolvimento desta pesquisa centra-se na relevância e atualidade do tema, que diz respeito aos modos de existência contemporâneos, ressaltando as mudanças que se inscrevem no cotidiano do trabalho.

Cabe destacar, ainda, que esta cartografia tem a internet como objeto e veículo de pesquisa. A pesquisa na internet ainda é recente, sendo utilizada, mais comumente, como fonte para buscar literatura e publicar resultados. Pesquisas que não se restringem a essas esferas caracterizam-se, em sua maioria, como levantamentos quantitativos online, questionários com base na web ou experimentos na internet. Contudo, o uso da internet com a finalidade de desenvolver pesquisa qualitativa está em expansão (FLICK, 2009). A ampla utilização desse canal de comunicação e informação começa a impulsionar também outras abordagens.

As pesquisas qualitativas na internet podem ser desenvolvidas por e-mail ou via web. As vantagens estão associadas à multiplicidade de dados acessíveis, a não restrição geográfica, à amplitude de públicos com os quais se pode contatar, à redução de custos etc. Entretanto, alguns cuidados são sinalizados e recaem, principalmente, sobre a confiabilidade dos dados; até mesmo, os demográficos. Se sexo, idade e raça são aspectos cruciais para a pesquisa, esta pode ficar comprometida, restringindo-se aos aspectos alegados pelos

\footnotetext{
${ }^{4}$ Blog é o nome dado a um tipo particular de site. Ele funciona como uma espécie de diário online, no qual são inseridos textos (chamados de posts), imagens, links etc. sobre um determinado tema ou temas variados, de acordo com sua proposta. O blog pode ser individual, quando uma pessoa é responsável pelas postagens, ou coletivo, quando mais pessoas compartilham sua autoria. É comum os blogs reservarem um espaço de interação ou comentários dos leitores, o que os torna mais atrativos.
} 
participantes, o que, por outro lado, pode garantir maior anonimato ao participante. Outro aspecto a ser destacado é que, embora, o alcance da internet seja amplo, ele não é universal. Há aqueles que não podem ou não querem estar conectados. Isso deve ser considerado no planejamento da pesquisa. Além disso, outro fator importante na discussão sobre pesquisa qualitativa na internet diz respeito à adesão dos participantes à pesquisa. Nesse sentido, Flick (2009) recomenda que se tenha em mente que nem sempre quem está disponível na internet está interessado em fazer parte de algum estudo. ${ }^{5}$

Cabe destacar, ainda, que, apesar desta pesquisa lançar mão da internet como campo (ao tomar como espaçoveículo um blog, ou seja, espaço que não existe na esfera off-line) esta não é tomada como uma benesse de antemão. Diferentemente do que ocorre entre alguns estudiosos que tendem a idealizá-la ou rejeitá-la, tratase aqui de conhecer mais de perto as possíveis contribuições da internet para a efetivação de conexões e seus reflexos nos modos de trabalhar-viver; no caso, mais especificamente, nos modos de trabalhar na saúde e da produção de si enquanto trabalhador da saúde: nos modos de "produzir(-se) ponto com" outros trabalhadores.

A expectativa é a de que, ao trazer método e objeto de certo modo inovadores para o campo de pesquisas em administração, sejam propiciadas leituras diferenciadas sobre fenômenos da atualidade, possibilitando desse modo diferentes perspectivas de entendimento acerca da relação trabalho-subjetividade no cenário contemporâneo.

\section{Subjetividade, Trabalho e a Cartografia}

O método cartográfico, proposto por Deleuze e Guattari, vem sendo utilizado em pesquisas de campo voltadas para o estudo da subjetividade. Entende-se por subjetividade um sistema complexo e heterogêneo, composto pelo indivíduo e pelas inúmeras relações que ele estabelece. Ela é construída histórica e socialmente e diz respeito à constituição de modos de existência e estilos de vida. Assim, a subjetividade não se configura como algo abstrato, mas "trata-se da vida, mais precisamente, das formas de vida, das maneiras de sentir, de amar, de perceber, de imaginar, de sonhar, de fazer, mas também de habitar, de vestir-se, de se embelezar, de fruir, etc." (PELBART, 2000, p. 37).

A subjetividade não se refere à estrutura, a objetos, a um mundo prévio ou a uma realidade pré-social, mas diz respeito às relações de forças e fluxos estabelecidas em movimento. Ela está constantemente em produção, fabricada e modelada no registro social e do qual é, portanto, indissociável (GUATTARI e ROLNIK, 1986). O processo no qual a subjetividade é gerada é constituído por práticas materiais das instituições sociais, tais como a prisão, a família, a fábrica e a escola, sendo assumida e vivida por indivíduos em suas existências particulares.

O modo pelo qual os indivíduos vivem essa subjetividade oscila entre dois extremos: uma relação de alienação e opressão, na qual o indivíduo se submete à subjetividade tal como a recebe, ou uma relação de expressão e de criação, na qual o indivíduo se reapropria dos componentes da subjetividade, produzindo um processo [...] de singularização. (GUATTARI e ROLNIK, 1986, p. 33)

Pensar a relação subjetividade-trabalho remete à análise da maneira como os sujeitos vivenciam e dão sentidos às experiências de trabalho, que conformam modos de agir, conhecer, sentir etc. (TITTONI e

\footnotetext{
${ }^{5}$ A reflexão aprofundada sobre esse aspecto não será foco deste artigo, para o que se indica a leitura de Flick (2009), Fragoso, Recuero e Amaral (2011), Mann e Stewart (2004) e Markham e Baym (2009). Contudo, para os objetivos deste artigo é importante ressaltar que as desvantagens assinaladas ou as limitações da pesquisa qualitativa na internet não comprometem o desenvolvimento da pesquisa em questão, tendo em vista que o que importa no exercício da cartografia não são as essências ou a busca de uma suposta verdade, mas aquilo que os participantes avaliam como importante de ser expressado.
} 
NARDI, 2006). A relação subjetividade-trabalho supõe a ruptura das dicotomias entre indivíduo/coletivo, objetivo/subjetivo e interior/exterior, e tem mostrado uma relevância ímpar no contexto do capitalismo contemporâneo. Isto porque o regime neoliberal está fundamentado nas forças subjetivas, particularmente, no conhecimento e na criação, de forma que pode ser qualificado como capitalismo cognitivo (ROLNIK, 2006).

Desse modo, é instalada uma nova (e íntima) relação entre a subjetividade e o capital, que se infiltra nas esferas mais infinitesimais da existência, no corpo e na alma das pessoas (PELBART, 2003), diluindo barreiras que separavam e opunham economia, poder e saber. "A vida já não é produzida nos ciclos de reprodução que estão subordinados ao dia de trabalho; ao contrário, a vida é que infunde e domina toda a produção" (HARDT e NEGRI, 2005a, p. 387). A esfera capitalista estendeu-se do tempo de trabalho à organização do tempo de vida e o capital invadiu o núcleo de sua vitalidade, mobilizando-a a trabalhar. $\mathrm{O}$ tempo livre e as atividades culturais, cognitivas, relacionais etc. não são mais considerados exterioridades ao capitalismo, mas o novo terreno de modulação dos modos de produzir. Tornam-se requisitos dessa produção, a inteligência, a imaginação, a criatividade, a conectividade, a afetividade, "toda uma dimensão subjetiva e extraeconômica antes relegada ao domínio exclusivamente pessoal e privado, no máximo artístico" (PELBART, 2003, p. 24).

Essa condição confere relevância ao estudo da relação subjetividade-trabalho, sendo a cartografia uma das vias privilegiadas para fazê-lo, como assinalam diversos autores, para além de seus propositores (FONSECA e KIRST, 2003; KIRST, 2010; MAIRESSE, 2003; PASSOS, KASTRUP e ESCÓSSIA, 2009; ROLNIK, 2006; ROMAGNOLI, 2009, entre outros). A cartografia coloca-se como uma possibilidade de aproximação, abrangente e adequada, aos fluxos, linhas e forças que compõem um mapa de determinado território. Por território, aqui, compreendem-se as paisagens psicossociais nas quais o pesquisador está interessado e que pode ser percorrido através de múltiplas entradas, marcando caminhos e movimentos, constituindo-se de modo rizomático (DELEUZE, 2000), isto é, com uma lógica que privilegia as conexões e não as superfícies ou os limites externos. É como afirmam os geógrafos: "a cartografia - diferentemente do mapa: representação de um todo estático - é um desenho que acompanha e se faz ao mesmo tempo que os movimentos de transformação da paisagem" (ROLNIK, 2006, p.23).

A cartografia propõe o registro das transformações no território, o acompanhamento de percursos, nas conexões de redes e na implicação do pesquisador com eles. Assim, atenta aos processos que compõem a subjetividade e que se passam entre os estados instituídos, buscando abarcar a complexidade, resistindo às tendências reducionistas. Nesse sentido, a cartografia procura romper com a lógica cartesiano-positivista, caracterizada pela dicotomização das relações entre pesquisador e objeto, por uma pressuposta neutralidade e imparcialidade vinculadas a métodos de representação de objetos preexistentes com regras estabelecidas de antemão. A cartografia "traz um novo patamar de problematização, contribuindo para a articulação de um conjunto de saberes, inclusive, outros que não apenas o científico, e favorecendo a revisão de concepções hegemônicas" (ROMAGNOLI, 2009, p. 169-170). A cartografia rejeita a ideia de que conhecer é representar ou reconhecer a realidade, assumindo uma perspectiva construtivista. Conforme Kastrup (2009, p. 49), "a construção do conhecimento se distingue de um progressivo domínio do campo de investigação e dos materiais que nele circulam. Trata-se, em certa medida, de obedecer às exigências da matéria e de se deixar atentamente guiar, acatando o ritmo e acompanhando a dinâmica do processo em questão".

Nessa mesma linha de pensamento, Fonseca e Kirst (2003) argumentam que cartografar significa marcar o momento de um olhar, dessacralizando o momento de verdade, considerando que todo conhecimento referese a um efeito das contingências que o engendraram. Dessa forma, a cartografia demanda comprometimento do pesquisador, o qual deve fazer um traçado singular daquilo a que se propõe estudar. Está relacionada não apenas ao comprometimento, mas também com sua implicação e invenção, partindo do pressuposto de que o conhecimento é processual e indissociável do movimento da vida e dos afetos que acompanham esse pesquisador.

Tal perspectiva de conhecimento promove a ampliação da concepção de mundo, incluindo o plano movente das coisas, ou seja, seus processos de produção e sua dinâmica. Nesse método, teoria e prática, pesquisa e intervenção, sujeito e objeto, produção do conhecimento e produção da realidade são aspectos indissociáveis. 
Assim, conhecer "pressupõe implicar-se com o mundo, comprometer-se com sua produção" (ALVAREZ e PASSOS, 2009, p. 131).

Na cartografia não se estabelece um conjunto de regras a serem aplicadas, da mesma forma que não se determina um (único) caminho para atingir um fim. Enfatizando a experimentação na pesquisa, Passos, Kastrup e Escóssia (2009) propõem que a cartografia promove o que chamam de uma reversão metodológica: transformar o "meta-hodos" (etimologia de método) em "hodos-meta", aquilo que se constrói continuamente na caminhada da pesquisa. Estes autores explicam que "metá-hódos" significa: metá = reflexão, raciocínio, verdade + hódos $=$ caminho, direção. Com essa reversão metodológica, Passos, Kastrup e Escóssia (2009) estimulam que a caminhada, isto é, o processo de pesquisa, não seja apenas o meio para alcançar as metas, mas que tenha relevância em si; que no processo de caminhar sejam traçadas e retraçadas as metas, tornando-se "hódos-metá".

Trata-se, portanto, de um método que acolhe procedimentos mais abertos e inventivos, cujo rigor, imprescindível na esfera acadêmica, envolve explicitar a implicação com a realidade, com o compromisso e o interesse pela intervenção. Dessa forma, a cartografia postula um compromisso ético do ato cognitivo com a realidade criada (PASSOS, KASTRUP e ESCÓSSIA, 2009). O pesquisador que se dispõe a tal prática "leva no bolso um critério, um princípio, uma regra e um breve roteiro de preocupações - este, cada cartógrafo vai definindo e redefinindo para si, constantemente" (ROLNIK, 2006, p. 69).

Sem predeterminar procedimentos de pesquisa, regras ou protocolos, o método cartográfico utiliza pistas como referências que "concorrem para a manutenção de uma atitude de abertura ao que vai se produzindo e de calibragem do caminhar no próprio caminhar no percurso da pesquisa" (PASSOS, KASTRUP e ESCÓSSIA, 2009, p. 13). As pistas permitem descrever, discutir e coletivizar a experiência do cartógrafo (KASTRUP, 2009). Assim, são indicadas oito pistas, independentes, mas conectadas, para o trabalho cartográfico, as quais são sintetizadas a seguir.

\section{Pista 1 - A indissociabilidade entre pesquisa e intervenção}

Toda pesquisa é considerada uma intervenção, a qual inclui uma dimensão política; isto é, que opera sobre a organização da realidade. Segundo essa lógica, a pesquisa se concretiza na experiência, reagrupando saberfazer, distanciados pela lógica cartesiano-positivista. Dessa forma, instiga o pesquisador a não se fixar em conhecimentos prévios ao ingresso em campo. Tal noção sustenta-se no princípio da análise institucional de transformar para conhecer, ir obtendo respostas, e não conhecer primeiro como requisito para depois transformar (PASSOS e BARROS, 2009).

Esse é um processo que se opera por transversalidades. Segundo Barros e Passos (2009, p. 27), “operar na transversalidade é considerar esse plano em que a realidade toda se comunica. [...] A tecedura desse plano não se faz de maneira só vertical ou horizontal, mas também transversalmente". Além disso, ao indicar a indissociabilidade entre pesquisa e intervenção, os autores afirmam a necessária implicação do pesquisador. Não se trata apenas de incluir o pesquisador no campo de suas observações, o que já é promulgado pela pesquisa-participante. Tampouco parece suficiente problematizar a relação pesquisador-campo de investigação, aspecto trabalhado na pesquisa-ação. Trata-se aqui de aprofundar, também, as concepções de subjetividade e ciência com que se orienta a investigação.

Podemos incluir legitimamente no campo de pesquisa, os desejos, as curiosidades, as indagações e os pressupostos do pesquisador. Considerar essa implicação é um valioso dispositivo de trabalho em campo (ROMAGNOLI, 2009). É a partir de sua subjetividade que afetos e sensações irrompem, sentidos são dados e algo é produzido.

\section{Pista 2 - O funcionamento da atenção no trabalho do cartógrafo}

Kastrup (2009) trabalha a questão da atenção na cartografia. Esse aspecto é destacado, tendo em vista que, ao se deparar com o campo, o pesquisador precisa dirigir sua atenção para algo, embora ao se fixar em um 
aspecto tenda a negligenciar os outros. Um caminho para solucionar tal questão está na adoção da "atenção à espreita" - flutuante, concentrada e aberta - que utiliza todos os sentidos (KASTRUP, 2009, p. 48). Uma concentração sem foco. Nesse sentido, essa autora distingue quatro gestos da atenção cartográfica: o rastreio, o toque, o pouso e o reconhecimento atento.

O rastreio diz respeito à "varredura do campo" para localizar pistas, signos de processualidade. O toque, por sua vez, "é sentido como uma rápida sensação, um pequeno vislumbre, que aciona em primeira mão o processo de seleção" (KASTRUP, 2009, p. 42). Não há um tempo ou uma intensidade definidos para que ocorra, mas revela-se como um alerta, sinalizando onde focalizar a atenção. O pouso, terceiro gesto atencional, indica o fechamento do campo em uma parada da percepção (seja visual, auditiva ou outra qualquer), levando a uma mudança na escala da atenção (quando ocorre uma espécie de zoom) e a uma reconfiguração do campo. Por fỉm, o reconhecimento atento. Esse gesto, acionado pelo pouso, instiga à questão "o que está acontecendo?” A partir daí, efetua uma (re)aproximação do processo, de modo a se destacar seus contornos singulares. O fenômeno do reconhecimento é entendido como uma espécie de ponto de interseção entre percepção e ativação da memória, não sendo um circuito fechado, como o reconhecimento automático do objeto, mas uma possibilidade de ampliação da percepção.

\section{Pista 3 - Cartografar é acompanhar processos}

Cartografar um campo é um convite para habitar um território que, a princípio, não se habita. Desde esse ponto de vista, segundo Barros e Kastrup (2009), observa-se uma proximidade com a etnografia que acontece através da observação e/ou observação participante. Intervir e implicar-se no/com o campo demanda, assim, acompanhar processos. Na maioria das vezes, "quando tem início uma pesquisa cujo objetivo é a investigação de processos de produção de subjetividade, já há [...] um processo em curso. Nessa medida, o cartógrafo se encontra sempre na situação paradoxal de começar pelo meio, entre pulsações" (BARROS e KASTRUP, 2009, p. 58).

Mas a processualidade da cartografia não se refere apenas ao "ingressar no meio". A processualidade diz respeito ao modo de pesquisar. Os passos da pesquisa, tradicionalmente separados e organizados sequencialmente, não se separam na cartografia: "a processualidade está em todos os momentos - na coleta, na análise, na discussão dos dados e também [...] na escrita” (BARROS e KASTRUP, 2009, p. 58). Aliás, essas não são concebidas como etapas, mas passos que se sucedem sem parar.

Nesse contexto, uma prática recomendada é a manutenção de um diário de campo onde, através da escrita e/ou de desenhos, sejam relatadas tanto informações objetivas, quanto impressões despertadas na interação com o campo. Tais anotações "colaboram na produção de dados de uma pesquisa e têm a função de transformar observações e frases captadas na experiência de campo em conhecimento e modos de fazer" (BARROS e KASTRUP, 2009, p. 70).

\section{Pista 4 - Movimentos-funções do dispositivo na prática da cartografia}

A cartografia é praticada através das pistas, de estratégias e procedimentos concretos, que são encarnados em dispositivos. Kastrup e Barros (2009, p. 78) definem dispositivo seguindo a perspectiva de Foucault e Deleuze. Para eles, dispositivos são "máquinas de ver e falar", são linhas de força que trazem a dimensão do poder-saber, e também linhas de subjetivação que inventam modos de existir. "O dispositivo alia-se aos processos de criação, e o trabalho do pesquisador, do cartógrafo, se dá no desembaraçamento das linhas que o compõem - linhas de visibilidade, de enunciação, de força, de subjetivação" (KASTRUP e BARROS, 2009, p. 79). O dispositivo caracteriza-se por sua força em romper o que estava bloqueado à criação.

As autoras propõem três movimentos-funções, ao considerarem que a função do dispositivo realiza-se através dos seguintes movimentos: 1. "Movimento-função de referência" - que, mais regular, articula a variação e a repetição; 2. "Movimento-função de explicitação" - das linhas que participam do processo de produção em curso, percebidas pela exploração do território no qual se operam pesquisa e intervenção; e 3. 
"Movimento-função de produção e de transformação da realidade" - que, a partir do movimentoexplicitação, gera efeitos no território, alterando-o.

\section{Pista 5 - 0 coletivo de forças como plano de experiência cartográfica}

Essa pista indica "a gênese constante das formas empíricas, ou seja, o processo de produção dos objetos do mundo, dentre eles, os efeitos de subjetivação" (ESCÓSSIA e TEDESCO, 2009, p. 92). Ao lado dos contornos estáveis do que denominamos formas, objetos ou sujeitos coexistem planos de forças que os produzem.

As autoras assumem o coletivo diferentemente da perspectiva dicotômica que o situa em oposição a indivíduo. Desse ponto de vista, o coletivo é composto pelo plano das formas e pelo plano das forças, os quais, embora distintos, estão relacionados. Trata-se de um enfoque rechaçado pela pesquisa tradicional e que a cartografia busca reintegrar, ao mostrar a indissociabilidade entre a investigação das formas e sua dimensão processual.

A pesquisa cartográfica, tendo em vista seu caráter de transversalidade, intensifica a comunicação e a interrelação entre relações, além de ativar o plano coletivo de forças (ESCÓSSIA e TEDESCO, 2009). Dessa forma, conhecer é traçar seu processo constante de produção.

\section{Pista 6 - Cartografia como dissolução do ponto de vista do observador}

Essa pista, em conjunto com as noções de transversalidade e de implicação, compõe o plano de pesquisa cartográfica. Nesse processo, é exigido do pesquisador mais do que uma atitude descritiva ou neutra. Ele também requer a dissolução do distanciamento entre sujeito e objeto, em um percurso de implicação recíproca. A dissolução do ponto de vista do observador coloca o cartógrafo na posição paradoxal de "habitar a experiência sem estar amarrado a nenhum ponto de vista e, por isso, sua tarefa principal é dissolver o ponto de vista do observador sem, no entanto, anular a observação" (PASSOS e EIRADO, 2009, p. 123).

A cartografia constitui um método que assume uma perspectiva construtivista do conhecimento, evitando tanto o objetivismo quanto o subjetivismo; não devendo levar à afirmação da participação de interesses, crenças e juízos do pesquisador.

\section{Pista 7 - Cartografar é habitar um território existencial}

A cartografia pressupõe a imersão do cartógrafo no território que deseja conhecer. "O trabalho da cartografia não pode se fazer como sobrevoo conceitual sobre a realidade investigada. Diferentemente, é sempre pelo compartilhamento de um território existencial que sujeito e objeto da pesquisa se relacionam e se codeterminam" (ALVAREZ e PASSOS, 2009, p. 131). Os autores seguem a definição de território de Deleuze e Guattari, que o compreendem não como formação, mas como expressividade, como um lugar de passagem, em constante processo de formação.

Nesse sentido, o modo de pesquisar indicado passa pela ideia de habitar o território, "compor com o território existencial, engajando-se nele" (ALVAREZ e PASSOS, 2009, p. 135), numa posição de aprendiz, que cultiva sua disponibilidade para a experiência e uma relação de "saber com" e não "saber sobre", dizem os autores. Nesse processo, o cartógrafo não ingressa o território conhecendo, de antemão, o que pretende "buscar". O processo de habitação do território inicia com a receptividade afetiva, que não deve ser confundida com passividade. Nesse processo, afirmam os autores, menos do que execução de normas técnicas, é a disposição por compor com o território que possibilita habitá-lo.

\section{Pista 8 - Cartografia exige uma mudança das práticas de narrar}

A produção do conhecimento ocorre a partir de escolhas que o pesquisador faz. Tais escolhas, conforme Passos e Barros (2009), acontecem invariavelmente a partir de uma tomada de posição que tem implicações 
políticas. Cabe ressaltar que a política é entendida, aqui, em sentido ampliado, referindo-se à "forma de atividade humana que, ligada ao poder, coloca em relação os sujeitos, articula-se segundo regras ou normas não necessariamente jurídicas e legais" (PASSOS e BARROS, 2009, p. 151). Nesse sentido a narratividade do que é visto, ouvido e sentido assume também uma dimensão política, implícita na forma escolhida pelo pesquisador para exprimir suas experiências.

O exercício cartográfico indica, assim, uma reinvenção da narrativa. Indica que é preciso resistir às redundâncias comuns nos relatos de caso padrão, nos quais a repetição gera a clareza do caso, em uma linearidade causal. A proposta cartográfica implica uma desmontagem que remete à dissolvência do caso em si, de sua estrutura, permitindo que os microcasos e as microlutas que o permeiam componham também a cena. A narrativa da desmontagem não fecha uma figura, mas destaca suas conexões, seus movimentos, seus contraditórios (PASSOS e BARROS, 2009).

Além dessas pistas, é preciso ter cuidado com alguns riscos ao desenvolver uma cartografia. Romagnoli (2009) chama a atenção para dois deles: o primeiro risco é utilizar a cartografia como um modelo, formatando-a conforme as práticas cientificistas, operando não para a criação, mas para a reprodução. $\mathrm{O}$ segundo risco é, em oposição à dureza de outros métodos, desenvolver um trabalho sem fundamentação, apresentando um aglomerado de saberes desconectados e conceitualmente confusos. Atento a esses aspectos, a cartografia pode auxiliar na compreensão dos fenômenos de interesse do pesquisador no campo da subjetividade.

\section{Cartografando: o Relato de uma Pesquisa}

A experiência cartográfica relatada a seguir começa pelo contexto no qual ela se insere, por seu objetivo e seus pressupostos. A cartografia em questão guia-se pela lógica de seu título principal: "Produzir(-se) com", visando compreender a produção de subjetividades e as possibilidades de cooperação no contexto do trabalho imaterial, a partir das conexões estabelecidas em um blog na internet.

Parte-se do princípio de que produzir é imprescindível no âmbito das sociedades capitalistas; e na atualidade destaca-se a produção do imaterial. O trabalho imaterial constitui o novo paradigma de organização do trabalho, no qual o centro de valor encontra-se na inovação atrelada, entre outros, a atividades intelectuais criadoras e a descobertas científicas (GORZ, 2005; HARDT e NEGRI, 2005a, 2005b; LAZZARATO e NEGRI, 2001). O exercício do trabalho imaterial valoriza, além de produtos materiais, produtos intangíveis como entretenimento, sentimentos de confiança, segurança e de conforto despertados nos consumidores. Ao trabalho imaterial são essenciais a comunicação, o conhecimento, o afeto e a cooperação. O saber e a criatividade que levam à produção do conhecimento e à inovação como valor beneficiam-se da partilha e das trocas que se mostram produtivas. Ao contrário dos recursos materiais, quanto mais compartilhados esses elementos, mais produtivos eles se tornam, podendo ser comparados às formas de energia que, na era industrial, constituíam o principal motor da produtividade.

No conjunto de suas características, produzir vai tomando a vida como um todo, em sua criação e manutenção. Assim, os modos de produção são, eles próprios, modos de subjetivação. Daí, qualquer aproximação efetivamente crítica que se faça às análises da subjetividade - como demonstraram Deleuze e Guattari (2010) no sugestivo subtítulo de sua controversa obra "O anti-Édipo: capitalismo e esquizofrenia" implica articular produção subjetiva com produção econômica. Nas palavras dos autores: "assim, a indústria não é mais considerada numa relação extrínseca de utilidade, mas em sua identidade fundamental com a natureza como produção do homem e pelo homem" (DELEUZE e GUATTARI, 2010, p. 15). A vitalidade torna-se a matéria-prima por excelência, ratificando a indissociabilidade da coprodução - de bens, serviços e de subjetividades -, que se enfatiza pelo uso da expressão "produzir(-se)" presente no título da pesquisa. 
Produzir(-se) acontece por meio de relações, sempre "com": com outras pessoas, com objetos etc. Nessa perspectiva, destaca-se a cooperação como inerente ao trabalho imaterial. Nesse paradigma, as energias produtivas estão relacionadas aos meios de interação, comunicação e cooperação. A riqueza reside no comum, nos prazeres, desejos, capacidades e necessidades compartilhados, e é propriamente o objeto da produção. É essa cooperação que o capital busca capturar, envolvendo-a pelo discurso do trabalho em equipe, tornando-o um recurso instrumental, através do qual o outro é usado como meio para determinados fins. Contudo, nem tudo é passível de ser cooptado pelo capital. Sabe-se que há sempre linhas de fuga e que algo sempre lhe escapa. Assim, devemos indagar se as novas conexões instigadas pela cooperação são potentes para romper o modo de subjetivação "indivíduo" e propiciar um coletivo produtor de trabalho-vida que permita configurar um novo modo de subjetivação: "produzir(-NOS) com".

Atualmente, a possibilidade dessa configuração pode ser agenciada por recursos tecnológicos digitais. Entre eles, a internet mostra-se como uma ferramenta capaz de subsidiar a circulação ilimitada de informações, instigar a participação e a organização de coletivos diversos. A constituição de redes sociais via internet viabiliza novas formas de relacionar e produzir. À expressão inicial do título da pesquisa poder-se-ia acrescentar o "ponto", característico dos endereços (ainda que os comerciais) da internet, alterando-o para "produzir(-se) . com", ou "produzir(-se) ponto com".

Um mundo de trabalho-vida que se baseia em produção intelectual e informacional, nas relações e na cooperação parece um "mundo perfeito", se comparado aos trabalhos de concepção taylorista-fordista. Gradualmente, em diferentes proporções, conforme a localização no globo e estratos socioeconômicos, são retirados de cena os ambientes de confinamento com problemas de iluminação, de temperatura e de ruídos. São resgatados saberes, emoções e a criatividade do trabalhador, que não se alienaria mais pela expropriação de sua força e seu tempo de trabalho. Esse contexto, que se mostra aparentemente pleno de qualidades, precisa ser detalhadamente observado, aguçando-se o olhar sobre as linhas e forças que o compõem.

Se produzir é imprescindível nas sociedades capitalistas contemporâneas, e produzir e produzir-se são indissociáveis, todos os indivíduos deveriam estar envolvidos nesse processo. Contudo, constata-se que muitos estão excluídos ou fragilmente inseridos, precarizando a criação e a manutenção do trabalho-vida. Dessa forma, encontram-se alijados do centro de interesse social hegemônico, com poucos atrativos para o estabelecimento das relações, de estar/ser/produzir "com". A fragilidade dos laços não afeta apenas os marginalizados. Os "inseridos" vivem uma luta constante para se sustentarem em seus lugares, como já afirmavam Castel (1998) e Bauman (1999). As relações de cooperação deparam-se com situações de competição, tornando-se, conforme já assinalado, meramente instrumentais. Constitui-se, então, um cenário de vivências paradoxais, repleto de dilemas.

Nas conexões estabelecidas via internet, ao poder de divulgação, encontro e multiplicação aliam-se as possibilidades de pulverização, excesso e superficialidade. A liberdade coexiste com o controle. Nesse espaço, compor coletivos é tão fácil quanto desconectá-los. Com um simples apertar de botão, desresponsabiliza-se do compromisso mútuo.

Visto assim, pontuados os opostos, pode parecer que se trata de uma realidade dicotomizada. No entanto, a característica do trabalho em contexto de trabalho imaterial é mais de ambivalência. É uma realidade permeada pela tensão dos contraditórios, revelando-se híbrida e instável. Portanto, a cartografia mostra-se útil para sua compreensão, instigando vislumbrar as transversalidades operando no território, a partir do exercício de aproximações e afastamentos (indicado na pista 2), naquilo que, sem reforçar dualismos, remete aos pares: grupo-indivíduo; horizontalidade-verticalidade; produção-produção de si; e trabalho-vida offline-trabalho-vida online. 
O território em questão é um blog coletivo ${ }^{6}$ que diz respeito, a princípio, a uma política pública de saúde e que reúne trabalhadores, gestores e usuários do Sistema Único de Saúde (SUS).

Inaugurado em 2008, tem como proposta ser um site colaborativo, com o objetivo de oportunizar o encontro e a troca de experiências, promovendo o que eles denominam afetação recíproca. O blog está aberto à multiplicidade de visões, apostando na potência da inteligência coletiva. Seu conteúdo está inteiramente aberto na web, não sendo exigido nenhum tipo de cadastramento para que se possa conhecer o que é publicado em suas páginas. $\mathrm{O}$ cadastramento é requisitado apenas àqueles que desejam tornar-se participantes da comunidade, com direito de adicionar seu perfil, publicar posts ou realizar comentários e utilizar alguns outros serviços disponíveis, como o envio e o recebimento de mensagens. O blog conta, atualmente, com cerca de 8000 usuários cadastrados.

Os posts são exibidos, sem nenhuma seleção prévia, numa área de votação. Têm direito a voto os participantes do coletivo moderador. Para compor esse coletivo basta ser indicado por qualquer membro. Os posts podem ficar na área de votação por sete dias. Recebendo 10 votos, passam a ser exibidos na página principal. A ideia dos propositores do site é incentivar a autogestão, a moderação realizada pelo próprio coletivo.

A princípio, houve receio de "maus usos", mas até hoje não houve problema maior e pequenos desusos foram contornados pelos participantes através da ferramenta de comentários. Caso o post não receba o número mínimo de votos, fica disponível no blog individual de seu autor. Esses blogs individuais podem ser acessados por qualquer outro participante.

Há entre os participantes, os que exercem os papéis de editores e administradores. Aos editores são conferidas algumas permissões adicionais, restritas aos aspectos técnicos do blog, sem que interfiram no conteúdo. Os administradores, por sua vez, têm permissões plenas. São eles que administram o sistema em seus aspectos tecnológicos, desenvolvendo ferramentas e corrigindo problemas técnicos.

A escolha desse blog como campo de pesquisa está relacionada ao interesse e a pesquisas prévias sobre a produção de sentidos no trabalho em saúde. Além disso, a proposta colaborativa do blog - que nasce com o objetivo de cooperação - e seu funcionamento como coletivo autogestor justificam sua escolha. O blog está aberto aos diversos atores que compõem os serviços de saúde, sejam gestores, trabalhadores ou usuários, possibilitando um olhar ampliado para as questões de trabalho e de produção de subjetividade a partir das conexões cooperativas efetuadas por intermédio da internet. É preciso considerar, contudo, que tal escolha recai sobre um campo preparado e receptivo a discussões a respeito da produção coletiva, a qual envolve atores motivados pela perspectiva de um trabalho onde exista abertura para o diálogo, às trocas e à cooperação transdisciplinar. Tais características, portanto, têm sido consideradas como analisadores no processo da pesquisa.

Além das características do blog, a escolha do campo na área da saúde está atrelada a experiências anteriores de pesquisa. Através dessas experiências se reconhecem demandas e dificuldades da área no que diz respeito à possibilidade de articulação do trabalho coletivo - o trabalho em equipe. O trabalho em saúde, por sua complexidade e pelo intenso processo de especialização ocorrido em sua conformação histórica, requisita a estratégia de ação multiprofissional (PEDUZZI, 2001). Desse modo, cada profissional complementaria a ação do outro, visando à integralidade, compondo uma "nova totalidade" (CAMPOS, 1997), construindo um conhecimento ampliado. Quanto melhor a interação, maior a possibilidade de uma ação efetiva. As equipes, contudo, dificilmente apresentam-se como a referida totalidade. Geralmente, observa-se uma "justaposição

${ }^{6}$ A proposta da cartografia e os princípios gerais da pesquisa qualitativa indicariam a identificação do campo escolhido, desde que a isso não houvesse oposição por parte dos envolvidos na pesquisa, de forma a permitir melhor acompanhamento do processo desenvolvido. Neste artigo, isso não será possível, tendo em vista a regra estabelecida para publicação que não permite divulgar a autoria do trabalho. Como o campo é um blog na internet, sua explicitação poderia levar facilmente a tal reconhecimento. 
alienada de trabalhos: cada parcela apresentando-se como exercício autônomo e independente" (CAMPOS, 1997, p. 239).

O estudo na área da saúde possibilita avançar na compreensão do trabalho desenvolvido coletivamente quando se analisa o modo como a cooperação é articulada a partir de um novo suporte, a rede que opera na internet. Por fim, o trabalho em saúde também interessa por ser tipicamente um trabalho imaterial, envolvendo conhecimento, comunicação e contato, no qual perpassam sensação de conforto, bem-estar e satisfação (HARDT e NEGRI, 2005a). Mesmo com essas características, também sofreu no modelo industrial um processo de taylorização, respondendo às demandas de uma produção fragmentada e serializada. Questiona-se, então: Como resgatar o afeto, a comunicação e a cooperação nos modos de organização e gestão do trabalho em saúde, permitindo sua (re)imaterialização para adaptar-se ao novo paradigma econômico?

Antes da proposta de pesquisa, o blog já era acompanhado esporadicamente, e por suas características, revelava ser campo fértil para uma exploração mais aprofundada e sistematizada. Com as justificativas apresentadas, nota-se a implicação entre pesquisador e território, que precisa ocorrer, conforme indicado na pista 1. Além disso, o processo de pesquisa implica outra relação com o território; uma relação mais sistematizada, acompanhando os processos (pista 3) e habitando o território (pista 7), sem que seja adotada uma posição supostamente neutra de observação (pista 6).

O contato inicial para discussão da pesquisa aconteceu através de e-mail dirigido a um dos membrosfundadores e editor do blog. O e-mail comentava sobre o projeto de pesquisa e indagava qual a possibilidade de inserção e de acolhimento da ideia. O retorno foi imediato e positivo. Contudo, esse membro não manteve para si esse "contrato". Levou a proposta aos demais membros, apresentando a ideia. Essa atitude constituise como analisador, demonstrando desde então, o caráter horizontal das relações estabelecidas. Diversos participantes manifestaram interesse pela pesquisa e se dispuseram a colaborar. A ideia de cooperação no trabalho já se fez sentir naquele momento! Além de satisfação, despertou também um sentimento de responsabilidade, intensificada pelas expectativas mobilizadas.

Assim foram os primeiros passos rumo ao território. Tratava-se agora de seguir o caminho, imbuída de algumas ideias, movida por inquietações e curiosidade resultantes de experiências de pesquisa anteriores e também do contato com o referencial teórico esquematizado. A cartografia é assim: incentiva a levar para o território os conhecimentos prévios para dialogar com outros e formar novos saberes. Assim, o exercício de pensar a pesquisa instigou a formulação de algumas questões ou eixos problemáticos que, de início, revelavam-se interessantes disparadores de movimento em direção ao território. Essas questões foram divididas em três blocos.

O primeiro bloco de questões dizia respeito às possibilidades tecnológicas, consideradas em seu sentido amplo, de composição do território, envolvendo técnica e lógica subjacente. Perguntava-se: Que território é este? Quais são as linhas e as forças que o compõem, dando-lhe forma? Em que cenário ampliado (entre ciberespaço e realidade off-line) se insere? Articula-se a outras redes? O que o mantém operando? O que há de diferente nesse espaço e na equipe na vida-trabalho off-line? Há trabalho? Há cooperação? Tem finalidade em si ou meio de divulgação de políticas? Ambos?

O segundo bloco de questões referia-se aos processos de subjetivação produzidos nesse território. Perguntava-se: Que modos de subjetivação se produzem a partir das conexões mediadas pela internet, particularmente nesse blog? Quais atores compõem esse território? Que implicações acarretam as diferenças de gênero, geração, profissão e de área de trabalho no campo da saúde? Quais suas motivações para integrarem? Participam de outras redes? Compõe-se um modo de subjetivação "nós"?

O terceiro bloco de questões remetia, então, às possibilidades de cooperação. Perguntava-se: As conexões desse blog constituem-se de modo cooperativo? Como se dinamizam as relações entre as esferas cooperativas on-line e off-line? O que (des)anima a cooperação? O coletivo da rede possibilita o 
arrefecimento das relações competitivas, constituindo laços de solidariedade? Que forma de poder se instaura? Configura-se como uma rede de autogestão? Como circulam (ou não) as noções de hierarquia? Seduções?

Tais questões configuraram-se como pistas iniciais. Não eram questões que pediam, necessariamente, respostas. Abria-se, como previsto pelo método escolhido, às imprevisibilidades, às novas questões ou mesmo à mudança de perspectiva sobre o fenômeno estudado. No percurso da pesquisa, produzindo dados e analisando-os, na integração gradual com o território e nos movimentos de narração, buscava-se um diálogo constante com o território.

Esse diálogo ocorreu seguindo alguns procedimentos. Após o contato inicial, procedeu-se à leitura de todos os posts do blog, considerando a página principal (e não os blogs individuais). A leitura ainda não foi concluída, visto que ele está em constante atualização e seguirá até que seja dada por encerrada a etapa de pesquisa em campo. Esta tem sido uma leitura flutuante, de "atenção à espreita", como indica Kastrup (2009), de reconhecimento dos temas, dos participantes, dos padrões, dos desvios etc. Ao mesmo tempo, tem sido realizada outra leitura, mais focada, buscando conhecer o que os próprios participantes afirmam sobre o blog, sobre seu funcionamento, sobre a troca de experiências, afetos despertados e assim por diante. A partir daí criou-se um diário contendo os trechos referentes a esse tópico, bem como as percepções e outras indagações de quem está pesquisando. Para se ter uma noção da dimensão do blog, o documento com trechos específicos de "autoanálise" ou "autorreferência" apresenta hoje - considerando os anos de 2008,2009 e 2010 -, 64 páginas de documento tipo word, fonte arial, tamanho 10 e espaço simples. É um coletivo que produz e compartilha suas experiências com bastante intensidade - quantitativa e qualitativamente. Essa leitura também segue sendo desenvolvida.

Outra entrada em campo também está sendo efetuada pela elaboração de uma planilha com todos os posts do ano de 2010, no total de 630. Foram identificados em cada post: autor, cidade, data, imagem associada ao conteúdo ( $\operatorname{cim}$ ou não), conteúdo resumido, quantidade de comentários e respostas aos comentários. No desenvolvimento do trabalho, a dinâmica de comentários foi se mostrando interessante para a pesquisa, dando indícios de que trata de algo relevante. Nessa direção, decidiu-se categorizar os assuntos dos posts, com o intuito de verificar a existência ou não de algum padrão ou tema mobilizador de maior participação em comentários. Também estão sendo categorizados os comentários, diferenciando, basicamente, aqueles que estão sendo denominados de "Incentivo" e os que são de "Continuidade à Reflexão". Os comentários de Incentivo são aqueles que reforçam a ideia apresentada, parabenizam pela experiência efetuada no local de trabalho e encorajam a manutenção dos esforços. São comentários de reforço e de ordem afetiva. Os comentários de Continuidade à Reflexão tomam o post como ponto de partida para relacionar com outras experiências, outros pontos de vista, outros materiais para análise. São comentários mais reflexivos, impulsionando o debate, embora também carregados de afeto e respeito. Entende-se, conforme o objeto de pesquisa, que tais diferenças podem ser significativas para o processo de cooperação e produção. Algo ainda a ser considerado no bojo das análises posteriores e junto aos participantes do blog.

A relação mais direta com os participantes está acontecendo a partir da proposição de fóruns de discussão sobre o tema da pesquisa, conformando-se um dispositivo. O post inicial lançado no blog foi um convite mais formalizado de participação na pesquisa, explicitando seus objetivos e referenciais teóricos, ofertando a possibilidade de resolução de dúvidas. Entende-se que este se constituiu como momento de contratação da pesquisa.

Esse post obteve os 10 votos necessários para ingressar na página inicial no mesmo dia, o que não é muito comum e que se revela um importante analisador, juntamente com os comentários verbais. Os comentários, em sua maioria, foram de apoio à proposta, e alguns trouxeram algumas questões sobre o referencial teórico. Cabe esclarecer que os participantes do blog - sobretudo, os mais ativos -, são, em sua maioria, profissionais da área da saúde, de escolaridade superior; alguns deles, professores e pesquisadores da área. São, portanto, interlocutores que mostram interesse também nos aspectos que fundamentam a pesquisa. 
Após 10 dias, tempo considerado suficiente - levando em conta que se tratava da apresentação e que o post permaneceria no site -, foi lançado o segundo post. Este trazia a sistematização das considerações que os participantes faziam sobre o próprio blog, produto do levantamento das "autorreferências". A questão inicial abordava "qual o significado do blog para você?". Foram muitos comentários, e, para cada um, novas questões foram surgindo, produzindo um fórum de discussão no blog sobre o blog.

Esse diálogo ainda está acontecendo. É interessante observar a intensidade das participações, o envolvimento com a proposta. Esse é o post mais comentado na história desse blog. No entanto, mais que a quantidade de comentários, constata-se a qualidade dos mesmos, no sentido de serem textos longos, elaborados, revelando dedicação à reflexão e à escrita. Muitas vezes, há o recurso a músicas e a imagens para expressar opiniões. Nesse post, vai sendo reproduzida a estética que permeia o blog, de potência de criação.

Contudo, o processo de pesquisa ainda apresenta um caráter de "pesquisador-pesquisado", no qual as propostas dependem de quem está pesquisando. Considerando o tema, o coletivo em questão e a proposta de pesquisa, há espaço para maiores intervenções dos participantes, algo que talvez produza maior entrosamento. Isso pode ser favorecido através da realização de um chat, no qual o contato com os participantes será síncrono, ou seja, em que todos os envolvidos estejam conectados ao mesmo tempo. O chat poderá ocorrer no próprio blog, em sua "sala de bate-papo".

As leituras, a categorização, os posts-fóruns e o possível chat são os procedimentos que têm sido escolhidos para entrar em campo e habitar o território ou definir novas entradas em campo. Como mencionado anteriormente, cada território e cada pesquisador, a cada momento vai formular os seus caminhos metodológicos. Não há fórmula, nem pré-requisitos, sobretudo, de triangulações ou confirmações de dados.

Optou-se por desenvolver a cartografia dessa maneira porque: a) as diversas leituras têm propiciado maior familiaridade com o campo, de modo que, mesmo entrando no meio do processo, está sendo possível compreender sua dinâmica; b) mais do que compreender, está sendo possível vivenciar essa dinâmica, de modo que a pesquisa está se integrando ao objeto; c) a cada entrada, novas facetas são conhecidas, reconhecidas e reformuladas. Elas proporcionam diferentes ângulos e, consequentemente, diferentes interpretações que vão sendo realizadas concomitantemente. Isto é, as análises estão sendo efetuadas, à luz do referencial teórico, nesse mesmo momento em que se está em campo.

Esses procedimentos têm possibilitado acompanhar os movimentos e as conexões existentes nesse blog, e já se tem algumas impressões sobre como trabalho e cooperação são articulados nesse contexto. Contudo, ainda há um caminho a percorrer, e seria precoce lançar essas ideias como se fossem "resultados parciais". Não há um resultado a ser alcançado, um objeto a ser desvendado. É preciso permanecer no território, vivenciá-lo e conhecê-lo melhor, reconhecendo que essa permanência não passará despercebida, mas instigando uma intervenção.

\section{Considerações Finais}

O estudo das relações entre trabalho e subjetividade tem se mostrado relevante na área de gestão de pessoas, sobretudo, hoje em dia, quando a subjetividade está no centro do processo produtivo, trazendo consequências pessoais e sociais, com impacto nos modos de vida. Ao estudar essas relações por meio de pesquisas científicas, compete ao pesquisador buscar as melhores estratégias para compreender as interações e coproduções que permeiam tais relações. A cartografia vem se revelando uma alternativa relevante e compatível para atingir esse objetivo.

A cartografia consiste no acompanhamento de territórios psicossociais, de seus percursos e conexões. Envolve multiplicidades e diferenciações, além de exigir uma postura ético-estética de acolhimento do movimento, da fluidez e da complexidade próprios da vida, inerentes à constituição das subjetividades. 
A cartografia remete à reflexão sobre o fazer pesquisa, colocando em questão os fundamentos da pesquisa tradicional - aqueles que buscam a constatação dos fatos - e a sustentação da verdade. Ela rompe com a lógica cartesiano-positivista e reaproxima o pesquisador de seu objeto, sem pretensa neutralidade ou imparcialidade. Ao contrário, assume a necessária implicação e a inevitável intervenção. Dessa forma, demanda do pesquisador trilhar seu caminho sem (falsas) certezas e abrir-se ao território estudado. Demanda flexibilidade e disposição para o encontro com o inusitado. Sua riqueza situa-se na abertura para o que está "por vir", na indeterminação (de antemão) daquilo que se pretende conhecer. Essa é sua riqueza e, ao mesmo tempo, o maior desafio.

A cientificidade da cartografia não se centra nos mesmos parâmetros da ciência moderna, do modelo positivista. A avaliação de uma pesquisa cartográfica não pode ser realizada seguindo os parâmetros usuais, o que não significa falta de rigor. Sua cientificidade está atrelada a uma qualificada fundamentação teórica, além de exigir atenção às pistas apresentadas, que podem garantir confiabilidade e credibilidade ao estudo, indicadores de sua qualidade.

A cartografia não pressupõe o cumprimento de etapas subsequentes, como desenvolver primeiro a coleta de dados para depois analisá-los e, em seguida, realizar a escrita. Na cartografia, entrar, habitar e conhecer o território, bem como analisar, sentir e relatar se desenvolvem concomitantemente. Daí porque também não se fala em levantar dados, mas em produzi-los. O cartógrafo não coleta dados. Estes são colhidos, da mesma forma que um semeador colhe o que planta. Ao produzir uma pesquisa nessa perspectiva, produz-se mais que informações "sobre" outros sujeitos, produz-se com eles, produzimo-nos subjetivamente.

A experiência cartográfica relatada está em andamento. No entanto, é possível afirmar, ratificando a processualidade da proposta, que desde já se percebem indícios significativos da cooperação no trabalho por meio de um blog na internet. Observam-se também aspectos contraditórios, sobretudo, um jogo de forças na dinâmica online/off-line.

Portanto, aqui não são apresentados "resultados", no que diz respeito às respostas aos questionamentos lançados. Contudo, e o mais importante para as considerações deste artigo sobre o método, é possível afirmar a validade da cartografia, sua contribuição para compreender e intervir na "realidade". Ao propor este artigo divulgando a cartografia e compartilhando uma experiência de pesquisa, espera-se contribuir com a produção de conhecimento significativo na área, incentivando a busca por outras perspectivas sobre objeto, método e veículo de desenvolvimento da pesquisa. Conforme argumentado desde a introdução, considera-se que o conhecimento advindo de um único paradigma científico já não pode ser considerado suficiente. Manter-se sempre no porto seguro dos mesmos moldes de pesquisa, legitimados e tradicionais, instiga a questionar: Para que, então, pesquisar?

\section{Referências}

ALVAREZ, J.; PASSOS, E. Cartografar é habitar um território existencial. In: PASSOS, E.; KASTRUP, V.; ESCÓSSIA, L. (Orgs.). Pistas do método da cartografia: pesquisa-intervenção e produção de subjetividade. Porto Alegre: Sulina, 2009. p. 131-149.

BARROS, L. P.; KASTRUP, V. Cartografar é acompanhar processos. In: PASSOS, E.; KASTRUP, V.; ESCÓSSIA, L. (Orgs.). Pistas do método da cartografia: pesquisa-intervenção e produção de subjetividade. Porto Alegre: Sulina, 2009. p. 52-75.

BAUMAN, Z. Globalização: as consequências humanas. Rio de Janeiro: Jorge Zahar Editores, 1999.

CAMPOS, G. W. S. Subjetividade e administração de pessoal: considerações sobre modos de gerenciar o trabalho em equipe de saúde. In: MERHY, E. E.; ONOCKO, R. (Orgs.). Práxis en salud: desafio para lo público. São Paulo: Hucitec, 1997. p. 229-266. 
CASTEL, R. As metamorfoses da questão social: uma crônica do salário. 3. ed. Petrópolis: Vozes, 1998.

DELEUZE, G. Conversações. 3. reimp. Rio de Janeiro: Editora 34, 2000.

.; GUATTARI, F. O anti-Édipo: capitalismo e esquizofrenia. São Paulo: Editora 34, 2010.

ESCÓSSIA, L.; TEDESCO, S. O coletivo de forças como plano de experiência cartográfica. In: PASSOS, E.; KASTRUP, V.; ESCÓSSIA, L. (Orgs.). Pistas do método da cartografia: pesquisa-intervenção e produção de subjetividade. Porto Alegre: Sulina, 2009. p. 92-108.

FONSECA, T. M. G.; KIRST, P. G. (Orgs.). Cartografias e devires: a construção do presente. Porto Alegre: Editora da UFRGS, 2003.

FLICK, U. Introdução à pesquisa qualitativa. 3. ed. Porto Alegre: Artmed, 2009.

FRAGOSO, S.; RECUERO, R.; AMARAL, A. Métodos de pesquisa para internet. Porto Alegre: Sulina, 2011.

GORZ, A. O imaterial: conhecimento, valor e capital. São Paulo: Annablume, 2005.

GUATTARI, F.; ROLNIK, S. Micropolítica: cartografias do desejo. Petrópolis: Vozes, 1986.

HARDT, M.; NEGRI, A. Império. 7. ed. Rio de Janeiro: Editora Record, 2005a.

Multidão: guerra e democracia na era do Império. Rio de Janeiro: Editora Record, 2005b.

KASTRUP, V. O funcionamento da atenção no trabalho do cartógrafo. In: PASSOS, E.; KASTRUP, V.; ESCÓSSIA, L. (Orgs.). Pistas do método da cartografia: pesquisa-intervenção e produção de subjetividade. Porto Alegre: Sulina, 2009. p. 32-51.

; BARROS, R. B. Movimentos-funções do dispositivo na prática da cartografia. In: PASSOS, E.; KASTRUP, V.; ESCÓSSIA, L. (Orgs.). Pistas do método da cartografia: pesquisa-intervenção e produção de subjetividade. Porto Alegre: Sulina, 2009. p. 76-91.

KIRST, P. G. Transfotografia: o pixel em multidão. 2010. Tese (Doutorado em Informática na Educação) - Programa de Pós-Graduação em Informática na Educação - Universidade Federal do Rio Grande do Sul, Porto Alegre, 2010.

LAZZARATO, M.; NEGRI, A. Trabalho imaterial: formas de vida e produção de subjetividade. Rio de Janeiro: DP\&A Editora, 2001.

MAIRESSE, D. Cartografia: do método à arte de fazer pesquisa. In: FONSECA, T. M. G.; KIRST, P. G. Cartografias e devires: a construção do presente. Porto Alegre: Editora da UFRGS, 2003. p. 259-272.

MANN, C.; STEWART, F. Internet communication and qualitative research: a handbook for researching online. 2. reimp. Londres: Sage, 2004.

MARKHAM, A. N.; BAYM, N. K. Internet inquiry: conversations about method. Thousand Oaks: Sage, 2009.

MORIN, E. O problema epistemológico da complexidade. Lisboa: Publicações Europa-América, 1983.

PASSOS, E.; KASTRUP, V.; ESCÓSSIA, L. (Orgs.). Pistas do método da cartografia: pesquisa-intervenção e produção de subjetividade. Porto Alegre: Sulina, 2009.

.; BARROS, R. B. A cartografia como método de pesquisa intervenção. In: PASSOS, E.; KASTRUP, V.; ESCÓSSIA, L. (Orgs.). Pistas do método da cartografia: pesquisa-intervenção e produção de subjetividade. Porto Alegre: Sulina, 2009. p. 17-31. 
.; EIRADO, A. Cartografia como dissolução do ponto de vista do observador. In: PASSOS, E.; KASTRUP, V.; ESCÓSSIA, L. (Orgs.). Pistas do método da cartografia: pesquisa-intervenção e produção de subjetividade. Porto Alegre: Sulina, 2009. p. 109-130.

PEDUZZI, M. Equipe multiprofissional de saúde: conceito e tipologia. Revista de Saúde Pública, São Paulo, v. 35, n. 1, p. 103-109, 2001.

PELBART, P. A vertigem por um fio: políticas da subjetividade contemporânea. São Paulo: Iluminuras, 2000.

Vida capital: ensaios de biopolítica. São Paulo: Iluminuras, 2003.

ROLNIK, S. Cartografia sentimental: transformações contemporâneas do desejo. Porto Alegre: Sulina, Editora da UFRGS, 2006.

ROMAGNOLI, R. C. A cartografia e a relação pesquisa e vida. Psicologia \& Sociedade, v. 21, n. 2, p. 166-173, 2009.

TITTONI, J.; NARDI, H. C. Subjetividade e trabalho. In: CATTANI, A. D.; HOLZMANN, L. (Orgs). Dicionário de trabalho e tecnologia. Porto Alegre: Editora da UFRGS, 2006. p. 277-280.

TONELLI, M. J.; CALDAS, M. P.; LACOMBE, B. M. B.; TINOCO, T. Produção acadêmica em recursos humanos no Brasil: 1991-2000. RAE: Revista de Administração Eletrônica, v. 3, n. 1, p. 105-122, jan./fev./mar. 2003.

VIEIRA, M. M. F. Por uma boa pesquisa (qualitativa) em administração. In: VIEIRA, M. M. F; ZOUAIN, D. M. (Orgs.). Pesquisa qualitativa em administração. 2. ed. Rio de Janeiro: Editora FGV, 2006. p. 13-28.

ZANELLI, J. C. Pesquisa qualitativa em estudos da gestão de pessoas. Estudos de Psicologia, v. 7, número especial, p.79-88, 2002. 